5 Goreau, T. F., Ecology, 40, 67 (1959).

6 Marshall, S. M., and Orr, A. P., Sci. Rept. Gr. Barrier Reef Exped., 1, 94 (1931).

7 Yonge, C. M., Scient. Rep. Gr. Barrier Reef. Exped., 1, 13 (1931).

8 Yonge, C. M., Pap. Tortugas Lab. I, 29, 185 (1935).

9 Goreau, T. F., and Goreau, N. I., Biol. Bull., 118, 419 (1960).

${ }_{10}$ Goreau, T. F., and Yonge, C. M., Nature, 217, 421 (1968).

11 Hubbard, J. A. E. B., and Pocock, Y. P., Geol. Rdsch., 61, 598 (1972).

12 Goreau, T. F., Endeavor, 20, 32 (1961).

13 Young, D. K., and Rhoads, D. C., Mar. Biol., 11, 242 (1971).

14 Jackson, J. B. C., Mar. Biol., 14, 304 (1972).

15 Kaufman, A., Trier, R. M., Broecker, W. S., and Feely, H. W., J. Geophys. Res. (in the press).

16 Vaughan, T. W., J. Wash. Acad. Sci., 5, 591 (1915).

${ }^{17}$ Lewis, J. B., Axelsen, F., Goodbody, I., Page, C., and Chislett, G., Mar. Sci. Ms. Rep. McGill Univ., 10, 1 (1960).

${ }^{18}$ Hoffmeister, J. E., and Multer, H. G., Bull. Geol. Soc. Am., 75, 353 (1964).

\section{Possible Therapy for Capture Myopathy in Captured Wild Animals}

CAPTURE myopathy (so-called overstraining disease) in wild animals has gained increasing prominence over the past decade as attempts to capture remaining nuclei of rare species for relocation and restocking, are rendered abortive by high death rates. The proportion of deaths is usually highest in the calves and in gravid females. High death rates in diminishing animal species such as tsessebe (Damaliscus lunatus) have occurred in spite of all precautions, such as the use of a helicopter to reduce the time between alerting the subject animal and the placement of a syringe containing suitable immobilising compounds.

Investigation on a number of species including blesbok (Damaliscus dorcas) and wildebeest (Connochaetes taurinus), has shown that an acute metabolic acidosis seems to be the causative factor in several at least of the manifestations of capture myopathy and death. A fall in the blood $\mathrm{pH}$ and attendant factors, namely base excess, buffer base, plasma and total bicarbonate, occur most precipitously in those animals pursued intensively for short distances of 1 to $2 \mathrm{~km}$. The deaths, with symptoms of capture myopathy seem to be due mainly at least to acute and profound acidosis rather than, as was widely believed, to exhaustion and overstraining of muscles and vital organs.

The fall in blood $p \mathrm{H}$ continues after the animals have been captured. The crating of captive animals such as zebra (Equus burchelli) in itself causes acidosis, so that little or no abatement of the condition may be expected during subsequent transport.

We have treated the syndrome induced experimentally in nine wild zebra (weighing 200-250 kg) pursued over short distances. We infused them intravenously with $1,000 \mathrm{mEq}$ of sodium bicarbonate dissolved in Normosol solution. Normosol solution (Abbott, Johannesburg) contains the following ions: $\mathrm{Na}^{+}, 140 ; \mathrm{K}^{+}, 5 ; \mathrm{Mg}^{2+}, 3 ; \mathrm{Cl}^{-}, 98 ;$ acetate, 27; gluconate, $23 \mathrm{mEq} \mathrm{1}^{-1}$. Approximate $p \mathrm{H} \mathrm{7.4}$. This therapy was successful. Six animals were treated and all survived. The treatment, given over 5 to $10 \mathrm{~min}$, was carried out $30 \mathrm{~min}$ after capture and resulted in immediate and spectacular amelioration of the predominant clinical symptoms such as dyspnoea and cardiac dysfunction: heart and respiratory rates were slowed, and the heart sounds became clearly audible and defined. Skeletal muscular spasm, as evident in untreated animals was prevented, and there was an immediate improvement in the animals' reactions and general condition.

The three untreated animals died within $12 \mathrm{~h}$ apparently of pulmonary oedema with post mortem findings exhibiting characteristic lesions of capture myopathy.

We do not wish to oversimplify the problem presented by capture myopathy in conservation measures, nor exclude genetic or acquired predisposition. It does appear, however, that at least aspects of the acute phase of the syndrome may be remedied.

A. M. HARTHOORN

Nature Conservation Division, P. Bag X209, Pretoria

Faculty of Veterinary Science,

K. VAN DER WALT

\section{Onderstepoort}

Division Veterinary Services,

Kruger National Park,

P.O. Skukuza,

South Africa

Received July 8; revised September 28, 1973.

\section{Ribonuclease activity of wheat leaves and rust infection}

Remarkable changes in the levels and properties of ribonuclease (RNase) occur following the inoculation of a susceptible variety of flax (Linum usitatissimum L., var. Bison) with flax rust uredospores (Melampsora lini (Ehrenb.) Lev, race 3$)^{1}$. The increase in RNase activity occurs in two distinct phases; an early phase between 2 to $4 \mathrm{~d}$ after inoculation (early RNase) and a later phase, beginning $5 \mathrm{~d}$ after inoculation (late RNase). These increases in RNase activity are accompanied by substantial changes in the properties of the enzyme including thermal stability, diethylpyrocarbonate-sensitivity and substrate preference ${ }^{1}$. Further studies (A. K. C., M. S., and L. A. S., unpublished) have revealed that these changes in the properties of RNase are due, at least in part, to the formation of new RNase molecules. These have kinetic and catalytic properties that are quite distinct from both of those 'host' RNase from healthy flax cotyledons and 'rust' RNase from flax rust uredospores or from rust mycelium grown axenically in a chemically defined medium. That changes in late RNase activity are specifically elicited by compatible host-parasite interactions is indicated by the appearance of late RNase which is not detectable in a resistant variety of flax (Bombay) inoculated with race 3 of Melampsora lini ${ }^{1}$. Furthermore, the characteristic bimodal increase in RNase activity and the accompanying changes in various properties of the enzyme have been found in a number of other rust-infected plants including pine and Ribes (A. E. Harvey, A. K. C., M. S. and L. A. S., unpublished), and mechanical injury of the healthy host tissues causes a significant increase in the level of RNase. The enzyme remains strictly 'host-type', however, no change in its physical or catalytic properties being detectable (ref. 1 and A. E. Harvey, A. K. C., M. S., and L. A. S., unpublished). Here we describe the effect of inoculation with uredospores of three races $(56,56 \mathrm{~A}$ and Australian race 126 ANZ-6, 7) of wheat stem rust (Puccinia graminis (Pers.) f. sp. tritici Eriks. and E. Henn.) in causing quantitative and qualitative changes in the RNase activity of paired, near-isogenic lines of wheat (Triticum aestivum L.) derived from the variety Chinese Spring and carrying the alleles Sr6 and srE (refs 2 and 3), respectively. Both lines give susceptible reactions (infection type 4 (ref. 4)) with race $56 \mathrm{~A}$, independent of temperature. The homozygous recessive, sr6, imparts susceptibility (infection type 4) to races 56 and $126 \mathrm{ANZ}-6,7$. The dominant allele, $\mathrm{Sr} 6$, confers a temperature sensitive reaction to these races; resistance is expressed (infection type 0 (ref. 4)) at 19 to $21^{\circ} \mathrm{C}$ but breaks down (infection type 4) at higher temperatures $\left(25\right.$ to $\left.26^{\circ} \mathrm{C}\right)$. A few intercellular hyphae are produced at each infection site at 19 to $21^{\circ} \mathrm{C}$. These survive for several days and resume growth when infected plants are transferred to 25 to $26^{\circ} \mathrm{C}$; but, in our experience, the longer infected 